\title{
Ecosystem service change caused by climatological and non-climatological drivers: a Swiss case study
}

\author{
Daniela Braun, ${ }^{1,6}$ Rogier de Jong, ${ }^{1}$ Michael E. Schaepman, ${ }^{1}$ Reinhard Furrer, ${ }^{2}$ Lars Hein, ${ }^{3}$ Felix Kienast, ${ }^{4}$ \\ AND AleXANDER DAmM ${ }^{1,5}$ \\ ${ }^{1}$ Department of Geography, Remote Sensing Laboratories, University of Zurich, Winterthurerstrasse 190, Zurich 8057 Switzerland \\ ${ }^{2}$ Departments of Mathematics and Computational Science, University of Zurich, Winterthurerstrasse 190, Zurich 8057 Switzerland \\ ${ }^{3}$ Environmental Systems Analysis Group, Wageningen University, PO Box 47, Wageningen 6700 The Netherlands \\ ${ }^{4}$ Swiss Federal Research Institute WSL, Birmensdorf 8903 Switzerland \\ ${ }^{5}$ Eawag, Swiss Federal Institute of Aquatic Science and Technology, Dübendorf 8600 Switzerland
}

Citation: Braun, D., R. de Jong, M. E. Schaepman, R. Furrer, L. Hein, F. Kienast, and A. Damm. 2019. Ecosystem service change caused by climatological and non-climatological drivers: a Swiss case study. Ecological Applications 29(4):e01901. 10.1002/eap.1901

Abstract. Understanding the drivers of ecosystem change and their effects on ecosystem services are essential for management decisions and verification of progress towards national and international sustainability policies (e.g., Aichi Biodiversity Targets, Sustainable Development Goals). We aim to disentangle spatially the effect of climatological and non-climatological drivers on ecosystem service supply and trends. Therefore, we explored time series of three ecosystem services in Switzerland between 2004 and 2014: carbon dioxide regulation, soil erosion prevention, and air quality regulation. We applied additive models to describe the spatial variation attributed to climatological (i.e., temperature, precipitation and relative sunshine duration) and non-climatological drivers (i.e., random effects representing other spatially structured processes) that may affect ecosystem service change. Obtained results indicated strong influences of climatological drivers on ecosystem service trends in Switzerland. We identified equal contributions of all three climatological drivers on trends of carbon dioxide regulation and soil erosion prevention, while air quality regulation was more strongly influenced by temperature. Additionally, our results showed that climatological and non-climatological drivers affected ecosystem services both negatively and positively, depending on the regions (in particular lower and higher altitudinal areas), drivers, and services assessed. Our findings highlight stronger effects of climatological compared to non-climatological drivers on ecosystem service change in Switzerland. Furthermore, drivers of ecosystem change display a spatial heterogeneity in their influence on ecosystem service trends. We propose an approach building on an additive model to disentangle the effect of climatological and non-climatological drivers on ecosystem service trends. Such analyses should be extended in the future to ecosystem service flow and demand to complete ecosystem service assessments and to demonstrate and communicate more clearly the benefits of ecosystem services for human well-being.

Key words: climate change; land use change; regulating services; remote sensing; time series; trends.

\section{INTRODUCTION}

Ecosystem services (ES) have been defined as benefit humans obtain from ecosystems (Millennium Ecosystem Assessment, 2005) and as contribution from ecosystems to these benefits (TEEB, 2010; United Nations, 2014). They are essential for human well-being by providing provisioning (e.g., food, timber, freshwater), regulating (e.g., climate regulation, water purification, soil erosion prevention) and cultural (e.g., recreation, aesthetic) services. Global change has been threatening and affecting many ecosystems, thereby causing severe modifications

\footnotetext{
Manuscript received 12 January 2018; revised 13 February 2019; accepted 25 February 2019. Corresponding Editor: Nancy F. Glenn.

${ }^{6}$ E-mail: daniela.braun@geo.uzh.ch
}

in ES and related benefits for human well-being (Mooney et al. 2009, Nelson et al. 2013, Karp et al. 2015, Runting et al. 2017). It is important to monitor changes in ES to ensure future sustainable development of our planet, but also to identify the drivers of change and related spatial and temporal scales at which they operate (Rounsevell et al. 2010). A driver of change is defined as a direct or indirect ecological or humancaused factor affecting ecosystem processes, functioning, and eventually ES (Millennium Ecosystem Assessment, 2005). Direct drivers of change have an explicit effect on ecosystems such as land use and land cover change, climate change, pollution, and the occurrence of invasive species. Indirect drivers are more diffuse, such as demographic, economic, sociopolitical, cultural, scientific, and technological drivers. Since both direct and indirect 
drivers can act at different spatial and temporal scales, they complicate the monitoring of their respective impact on ES.

Climate change with its associated effects on temperature, precipitation and sea level rise is among the most frequently investigated direct drivers of dynamics in ES supply (Scholes 2016, Runting et al. 2017). The impact of climate change on ES is predominantly negative and varies cross ES, drivers, and assessment methods with stronger negative impacts on regulating and cultural ES compared to provisioning ES (Runting et al. 2017). Particularly the spatial variability of climatological drivers causes difficulties in the assessment and management of their impacts on ES. Further, the impact of ES change drivers is often complex with multiple drivers affecting state or condition of ecosystems. This complexity determines a changing capacity of ecosystems that, in combination with altered ecosystem use (e.g., through adaptation), eventually leads to dynamics in ES supply (e.g., Hein et al. 2015). Besides direct drivers, there are also indirect drivers of change due to socioeconomic pressures (e.g., population growth, demand for agricultural commodities, and pricing) that act simultaneously and can cause non-climatological drivers, for example, land cover and land use change. Land cover and land use change have been one of the most frequently studied non-climatological drivers with often negative impacts on ES (Polasky et al. 2011, Lawler et al. 2014, Egarter Vigl et al. 2017, Runting et al. 2017).

Investigating the influence of climatological and nonclimatological drivers simultaneously is essential to understand their complex interactions, and their relative and cumulative impact on ES change. Although an increasing number of studies assess the influence of ES change drivers, the focus has mainly been on selected individual drivers and their impact on ES supply as well as on predictions of ES under future climate and land use change scenarios (Runting et al. 2017). The assessment of multiple drivers and multiple ES is often neglected, only a few studies focus on several socioecological indicators to explain spatial variations in multiple ES (Meacham et al. 2016, Mouchet et al. 2017). However, it is known that mutual interactions of several simultaneous drivers on ES need to be considered to fully understand ES changes (Runting et al. 2017). Disentangling the contribution of all drivers including their individual and cumulative impact on ES alterations is a remaining problem. Furthermore, most known causal relationships between ES and change drivers are based on future projections of ES dynamics that only consider land use and climate change scenarios (Nelson et al. 2010, Lawler et al. 2014, Rosenzweig et al. 2014, Martinez-Harms et al. 2017). Still, few studies evaluate the effect of change drivers on actually measured ES trends (Nelson et al. 2013, Schirpke et al. 2013, Egarter Vigl et al. 2016, Guerra et al. 2016b). This determines a gap since identifying the actual impact of change drivers on ES allows evaluating the effect and efficiency of past decisions and can improve decision-making in landscape planning and conservation. We consequently hypothesize that monitoring approaches investigating actual ES and underlying change drivers affecting ES are essential. Such approaches allow facilitating environmental schemes that incorporate ES in their agenda, e.g., to monitor the efficiency of payments for provided ES, to assess the progress towards political targets regarding ES restoration (e.g., EU Biodiversity Strategy 2020, the Aichi Biodiversity Targets and the Sustainable Development Goals), and to reevaluate those measures if necessary.

The aim of this study is to investigate possibilities to disentangle spatially the effect of climatological and non-climatological drivers on ES supply and trends. We explored time series of three ES in Switzerland between 2004 and 2014, namely $\mathrm{CO}_{2}$ regulation, soil erosion prevention, and air quality regulation. We used an additive model to describe the spatial variation attributed to changes in climatological drivers (i.e., temperature, precipitation, and relative sunshine duration) and nonclimatological random effects representing other spatially structured processes possibly affecting ES change. We investigated non-climatological effects at regional scale to reveal their underlying causes (e.g., land use change due to political, economic, or environmental decision-making).

We realize that $11 \mathrm{yr}$ is a relatively short period to examine the effects of climate change on ES with climate variability affecting trends in climatic factors relatively strongly at such a short time frame. Nevertheless, we believe our approach is useful for studying the impacts of climatic trends on ES, even though these effects are likely to be more pronounced when studied at longer time frames.

\section{Methods \\ Study area}

Switzerland is located in central Europe with an area of approximately 4.1 million ha. The country covers altitudes ranging from $196 \mathrm{~m}$ to $4,634 \mathrm{~m}$ above sea level in four biogeographical regions: (1) the Jura, a low mountain range in the northwest, (2) the Swiss Midlands, lowlands crossing Switzerland from the west to the northwest, and the (3) Central and (4) Southern Alps, a mountain range covering about $60 \%$ of the country (Fig. 1).

Land use and land cover are characterized by urban and settled areas covering $7.5 \%$ of the country, agriculture $(35.8 \%)$, wooded areas $(31.3 \%)$, surface water (4.3\%), and remaining natural environment $(21.0 \%)$ (Swiss Federal Statistical Office, 2016). During the last $25 \mathrm{yr}$, the Swiss landscape has constantly changed due to urban expansion particularly in the Swiss Midlands (Jaeger and Schwick 2014) and due to land 


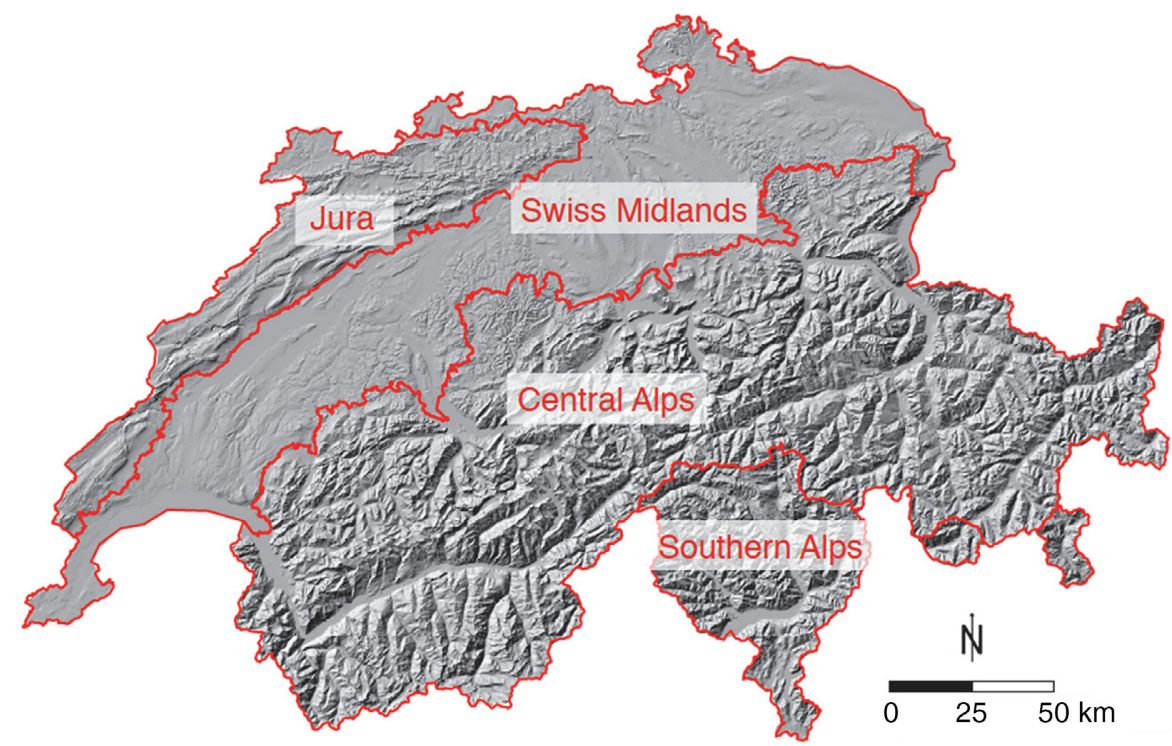

FIG. 1. The study area Switzerland with its different geographical regions. A digital elevation model is used as background (courtesy of Swisstopo).

TABLE 1. Overview of investigated ecosystem services (ES) and their input of data (cf. Braun et al. [2018] for details on the used methodology).

\begin{tabular}{lc}
\hline \hline ES, potential supply, and input data & $\begin{array}{c}\text { Spatial } \\
\text { resolution }(\mathrm{m})\end{array}$ \\
\hline $\mathrm{CO}_{2}$ regulation $\left(\mathrm{CO}_{2} \mathrm{R}\right)$, sequestered & \\
$\mathrm{CO}_{2}\left(\mathrm{~g} \mathrm{C} \cdot \mathrm{m}^{-2} \cdot \mathrm{yr}^{-1}\right)$ & 500 \\
$\mathrm{MODIS}$ land cover (MCD12Q1) & 500 \\
Net primary production (MOD17A3H) & 2,000 \\
Mean monthly air temperature & 2,000 \\
Mean monthly precipitation & \\
Air quality regulation (AQR), PM & \\
removal $\left(\mu \mathrm{g} / \mathrm{m}^{2}\right)$ & 500 \\
MODIS: Leaf area index (LAI) & \\
$\quad$ (MOD15A2H) & 500 \\
Land cover (MCD12Q1) & 200 \\
Annual PM 10 concentrations & \\
Dry deposition velocity for PM & \\
Soil erosion prevention (SEP), potential & \\
soil erosion (Mg/ha) & \\
MODIS: NDVI (MOD12A1) & 500 \\
Digital elevation model & 25 \\
Rainfall erosivity & 500 \\
Soil erodibility & 500 \\
\hline
\end{tabular}

abandonment in Alpine areas followed by expansion of wooded areas (Gellrich et al. 2007).

\section{Data}

Ecosystem service time series.-We investigated time series of three ES, namely $\mathrm{CO}_{2}$ regulation $\left(\mathrm{CO}_{2} \mathrm{R}\right)$, soil erosion prevention (SEP), and air quality regulation (AQR; Table 1) between 2004 and 2014 with annual time increments. The investigation period is limited due to the availability of all input data. The calculation of ES is outlined hereafter, more details on the ES models and data used can be found in Braun et al. (2018). We used linear regression analysis to derive ES trend maps with a $1-\mathrm{km}$ spatial resolution and resampled them to $2 \mathrm{~km}$ (bilinear interpolation) to match the spatial resolution of investigated climatological variables (cf. Appendix S1: Fig. S2a-c for significant trends).

Note that the recent IPBES classification followed a different typology and uses the concept of "nature's contributions to people" instead of ecosystem services (see Díaz et al. 2015). However, we maintain the term ES in order to be aligned with SEEA, CICES, as well as our earlier work (Braun et al. 2018).

1. $\mathrm{CO}_{2}$ regulation. $-\mathrm{CO}_{2}$ regulation represents the role of vegetation in mitigating climate change and was defined as net ecosystem production (NEP) without considering harvest losses due to a lack of temporally and spatially explicit harvest data. NEP $\left(\mathrm{g} \mathrm{C} \cdot \mathrm{m}^{-2} \cdot \mathrm{yr}^{-1}\right)$ was estimated according to Schröter et al. (2014) as the difference of annual net primary production (NPP; $\mathrm{g} \mathrm{C} \cdot \mathrm{m}^{-2}$. $\left.\mathrm{yr}^{-1}\right)$ and annual soil respiration $\left(R_{S} ; \mathrm{g} \mathrm{C} \cdot \mathrm{m}^{-2} \cdot \mathrm{yr}^{-1}\right)$ as:

$$
\begin{gathered}
\mathrm{CO}_{2} \mathrm{R}=\mathrm{NEP}=\mathrm{NPP}-R_{S}, \text { with } \\
R_{S}=\sum 1.250 \cdot e^{\left(0.05452 \cdot T_{a}\right)} \cdot\left(\frac{P}{4.259+P}\right) .
\end{gathered}
$$

Annual NPP was derived from the annual MODIS NPP (MOD17A3H) product (Running and Zhao 2015). Annual $R_{S}$ was calculated according to Raich et al. (2002) as yearly sum ( $\Sigma$ ) of mean monthly air 
temperature $\left(T_{\mathrm{a}} ;{ }^{\circ} \mathrm{C}\right)$ and mean monthly precipitation $(P ; \mathrm{mm})$ provided in $2 \mathrm{~km}$ spatial resolution (Meteo Swiss 2013). Braun et al. (2017) showed in their landscape scale study that estimates of $R_{\mathrm{S}}$ and associated NEP partly deviate from flux tower observation for certain land cover types (e.g., grassland), due to the double accounting of below ground respiration and the coarse spatial resolution of used monthly meteorological data.

2. Air quality regulation.-Air quality regulation describes the ability of vegetation to filter aerosols from the atmosphere. It was calculated as yearly sum $(\Sigma)$ of integrated daily measurements representing the vertical capture of particulate matter of less than $10 \mu \mathrm{m}\left(\mathrm{PM}_{10}\right)$ by ecosystems (Nowak 1994, Manes et al. 2016) as

$$
\mathrm{AQR}=\sum C \cdot V_{d} \cdot \mathrm{LAI} \cdot T \cdot 0.5 .
$$

$C$ is the $\mathrm{PM}_{10}$ concentration in the air $\left(\mu \mathrm{g} / \mathrm{m}^{3}\right)$ and was provided by the Swiss Federal Office for the Environment (2015), $V_{d}$ is the dry deposition velocity for $\mathrm{PM}_{10}(\mathrm{~m} / \mathrm{s})$, a constant reported in Remme et al. (2014), LAI is the leaf area index $\left(\mathrm{m}^{2} / \mathrm{m}^{2}\right)$ represented by the MODIS LAI product (MOD15A2H; Myneni et al. 2015), $T$ is the time step (here corresponding to $1 \mathrm{yr}$ ), and 0.5 is the suspension rate of deposited $\mathrm{PM}_{10}$ returning back to the atmosphere (Zinke 1967).

3. Soil erosion prevention.-We defined SEP according to Guerra et al. (2016a) as the difference between the structural impact $\Upsilon$ (e.g., the total soil erosion impact in the absence of soil erosion prevention is the potential soil erosion) and the remaining ES mitigated impact $\beta$ (i.e., the remaining soil erosion that was not regulated by soil erosion prevention) as

$$
\begin{gathered}
\text { SEP }=\Upsilon-\beta=\Upsilon\left(1-C_{V}\right), \text { with } \\
\Upsilon=R \cdot K \cdot \mathrm{LS}
\end{gathered}
$$

where $\Upsilon$ is the structural impact ( $\mathrm{Mg} / \mathrm{ha}), C_{V}$ is the vegetation cover $(-), R$ is the rainfall erosivity $\left(\mathrm{MJ} \cdot \mathrm{mm}^{-1} \cdot \mathrm{ha}^{-1}\right.$. $\mathrm{h}^{-1}$; Panagos et al. 2015), $K$ is the soil erodibility ( $\mathrm{Mg}$ ha $\mathrm{h} \mathrm{ha}^{-1} \mathrm{MJ}^{1} \mathrm{~mm}^{-1}$; Panagos et al. 2014), and LS describes the effect of topography on soil erosion (-), estimated with the terrain analysis module of the System for Automatic Geoscientific Analysis (SAGA) software (Pilesjö and Hasan 2014). Vegetation cover $C_{V}$ was estimated as a function of NDVI as suggested by Guerra et al. (2016a):

$$
C_{V}=\exp \left[-2 \cdot \frac{\mathrm{NDVI}}{(1-\mathrm{NDVI})}\right]
$$

The MODIS NDVI product (MOD13A1; Didan 2015 ) was used to calculate the vegetation cover $C_{V}$. Further details about this ES estimation can be found in Guerra et al. (2016a) and in Braun et al. (2018).
The calculation of ES incorporates three MODIS products (i.e., NDVI, LAI, NPP) related to vegetation density. However, retrieval concepts underlying these MODIS products substantially differ and the products represent different plant trait categories including structural (LAI), a combination of structural and biochemical (NDVI), and functional (NPP) traits. Further, the combination of MODIS products with environmental variables using linear and nonlinear functions to obtain ES resulted in a highly nonlinear influence of underlying MODIS products across retrieved ES.

Climatological data.-MeteoSwiss provided annual mean temperature, precipitation, and relative sunshine duration data from 2004 to 2014 with a spatial resolution of $2 \mathrm{~km}$ (MeteoSwiss, 2016). The annual temperature (version 1.4) and precipitation data (version 1.0) were obtained from spatial interpolation of in situ measurements of about 80 weather stations and 420 rain gauges in Switzerland (MeteoSwiss 2016). Annual relative sunshine duration data (version 1.2) were based on a combination of in situ heliometer measurements of about 70 stations and high-resolution satellite imageries (MeteoSwiss 2016). We calculated trends for all three climatological drivers by linear regression (Appendix S1: Figs S1 and S2d-f for significant trends).

Changes in climatological drivers can cause alterations in ecosystem properties, functioning and eventually ES. We particularly selected temperature, precipitation, and sunshine duration, assuming that they show complex positive or negative effects on ES (Fig. 2). For example, all three climatological drivers negatively influence SEP, since changes in them have negative effects on vegetation growth. AQR shows highly complex dependencies on climatological drivers (Jacob and Winner 2009). Increasing precipitation, for example, can have a positive effect on air quality itself (reduction of $\mathrm{PM}_{10}$ ) but might cause a negative effect on $\mathrm{AQR}$ : $\mathrm{AQR}$ is dependent on $\mathrm{PM}_{10}$ concentrations, means less $\mathrm{PM}_{10}$ in the atmosphere implies that less $\mathrm{PM}_{10}$ can be filtered by vegetation, causing a reduced provisioning of $A Q R$. Similar to $\mathrm{AQR}, \mathrm{CO}_{2} \mathrm{R}$ shows complex dependencies on investigated climatological drivers while a change in these drivers can possibly have a positive or negative effect on $\mathrm{CO}_{2} \mathrm{R}$ : Less organic biomass will be decomposed due to less precipitation resulting in less $\mathrm{CO}_{2}$ losses due to heterotrophic respiration and an increase in $\mathrm{CO}_{2} \mathrm{R}$. However, vegetation might reduce its photosynthetic activity and, thus, NPP due to limited water availability, resulting in a decrease in $\mathrm{CO}_{2} \mathrm{R}$.

\section{Determination of climatological and non-climatological effects}

We used an additive model to describe observed temporal changes in ES ( $y$, response). The model contained a deterministic part $g(x)$, where $y$ depends on a set of covariates $x$ with their coefficients, a spatial process $h$ 


\begin{tabular}{|c|c|c|c|}
\hline & $\begin{array}{c}\mathrm{CO}_{2} \\
\text { regulation }\end{array}$ & $\begin{array}{l}\text { Soil erosion } \\
\text { prevention }\end{array}$ & $\begin{array}{l}\text { Air quality } \\
\text { regulation }\end{array}$ \\
\hline Temperature & $\begin{array}{c}- \\
(16- \\
(10)\end{array}$ & $\begin{array}{c}- \\
(6-15)\end{array}$ & $\begin{array}{l}- \\
(1)\end{array}$ \\
\hline Precipitation $\boldsymbol{\uparrow}$ & $\begin{array}{c} \pm \\
(6-15)\end{array}$ & $\begin{array}{c}- \\
(6-15)\end{array}$ & $\begin{array}{l}- \\
(1)\end{array}$ \\
\hline Precipitation $\downarrow$ & $\begin{array}{c} \pm \\
(16-30)\end{array}$ & $\left.\begin{array}{lr}- & \pm \\
(6- & 15\end{array}\right)$ & $\begin{array}{l}+ \\
\text { (1) }\end{array}$ \\
\hline $\begin{array}{l}\text { Relative sunshine } \\
\text { duration }\end{array}$ & $\begin{array}{c} \pm \\
(2-5)\end{array}$ & $\begin{array}{l}- \\
(1)\end{array}$ & $\begin{array}{l}+ \\
(1)\end{array}$ \\
\hline
\end{tabular}

FIG. 2. The impact of climatological drivers on ecosystem services (ES; based on Runting et al. [2017] and Jacob and Winner [2009]). The influence of climatological drivers on ES can be positive $(+$, blue color), negative $(-$, red color $)$, or mixed $( \pm$, green color), when studies found both positive and negative effects. The color represents the certainty level of the causal relationships and was estimated from several studies (number of studies are added in brackets below the sign). The darker the color, the higher is the certainty level.

representing all non-climatological drivers that may influence ES and a residual component $\varepsilon$ (de Jong et al. 2013):

$$
y=g(x)+h+\varepsilon .
$$

We adapted this model by using a random forest ( $\mathrm{R}$ package randomForest, version 4.6; Liaw and Wiener 2002) as deterministic part to model the influence of climatological drivers on ES change. We refer to the following modeled deterministic component as $D C$. The relationship between ES and climatological drivers may depend on biogeographical regions because of their distinctly different nature, e.g., mountains vs. midlands, which render simple linear models inadequate. For this, we split the data set into training $(70 \%)$ and test $(30 \%)$ parts and set the number of trees to 1,000 . The contribution of the individual climatological drivers to the overall modeled deterministic component of each ES was estimated by calculating the importance of the variable based on mean decrease in accuracy using the R package caret (Kuhn 2015; version 6.071). The direction of the relationship between climatological drivers and the explained variation in ecosystem services was based on the sign of the respective correlation coefficients.

The spatial process was estimated from the remaining spatial variance of observed changes in ES and the modeled deterministic component $y-D C$ and may be attributed to effects by non-climatological drivers or to interactions that cannot be explained by the climatological drivers. A transformation of $y-D C$ per ES was necessary to meet the stationarity assumption of the spatial process model (transformation $\mathrm{CO}_{2} \mathrm{R}, \log (y-D C)$; SEP, $(y-D C)^{0.25}$; AQR, $\left.(y-D C)^{0.2}\right)$. Before the transformation, the absolute minimum value per ES was added to account for negative values.

The related spatial process $h$ was modeled by a Gaussian process having zero mean and a parameterized spherical covariance function (de Jong et al. 2013): a range parameter that represents the length of the spatial dependence and a sill parameter that describes the marginal variance. We term the variance of the white noise component as the nugget. The initial sill and nugget were estimated by method-of-moments using gstat sample variograms (Pebesma and Wesseling 1998) and the range between 0.1 and 1.2 degrees $(\sim 135 \mathrm{~km})$ was tested using maximum likelihood estimation to assess the length of the spatial dependence. In order to account for the heterogeneous topography of Switzerland, we set the range to 1.2 degrees $(\sim 135 \mathrm{~km})$ for all ES. The residuals were calculated as the difference between the observations, the modeled deterministic component $D C$ and the spatial process $h$ (Eq. 7) after reversing the transformation.

The standardized ratio index between effects of climatological and non-climatological drivers $(R I)$ indicates which type of driver was strongest in explaining the spatial variance in ES trends and was calculated as

$$
R I=-1+\frac{2 \cdot|D C|}{|D C|+|h|}=\frac{|D C|-|h|}{|D C|+|h|} .
$$

Positive values of $R I$ represented a stronger influence of climatological drivers with 1 being only affected by climatological drivers, while negative $R I$ values represented influences of non-climatological drivers with -1 being completely without influence of climatological drivers. $R I$ equals zero indicated the same contributions of effects by climatological and non-climatological drivers to ES change. Additionally, the influence of climatological drivers on ES change was estimated by calculating the coefficient of determination $\left(R^{2}\right)$ of the observed ES change and the modeled deterministic component $(D C)$ as quotient of the residual sum of squares and the total sum of squares:

$$
R^{2}=\frac{\sum\left(y_{i}-D C_{i}\right)^{2}}{\sum\left(y_{i}-\bar{y}\right)^{2}}
$$

where $y_{i}$ are the values of observed ES change, $D C_{i}$ are the predicted values of ES change due to effects by climatological drivers, and $\bar{y}$ is the mean value of the observed ES change.

\section{RESUlts}

\section{Effects of climatological drivers on ES change (deterministic component $\mathrm{g}(\mathrm{x})$ )}

The modeled deterministic component $g(x)$ described the effect of climatological drivers on ES change. The spatial variation in ES change was well captured by the random forest models (Fig. 3b) indicated by $R^{2}$ values of 0.63 for SEP followed by 0.54 for AQR and 0.40 for $\mathrm{CO}_{2} \mathrm{R}$ (Table 2). At regional scale, the Jura and Swiss Midlands obtained the highest spatial variance 
$\mathrm{CO}_{2}$ regulation $\left(\mathrm{kg} \mathrm{C} \cdot \mathrm{m}^{-2} \cdot \mathrm{yr}^{-1}\right)$

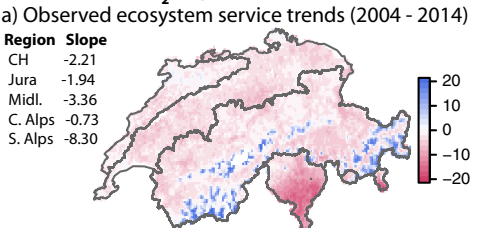

b) Ecosystem service trends explained by climatologies

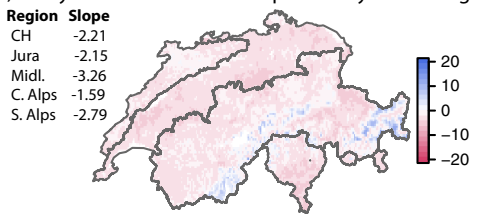

c) Ecosystem service trends explained by non-climatological effects

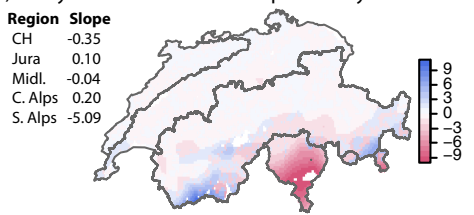

d) Ratio of climatological and non-climatological effects

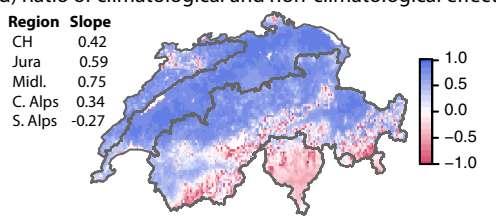

Soil erosion prevention $(\mathrm{Mg} / \mathrm{ha})$
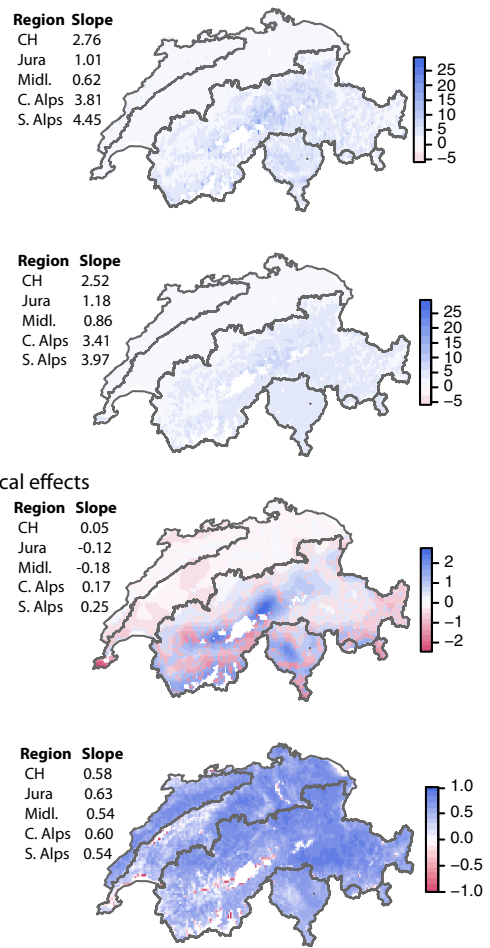

Air quality regulation $\left(\mathrm{g} / \mathrm{m}^{2}\right)$
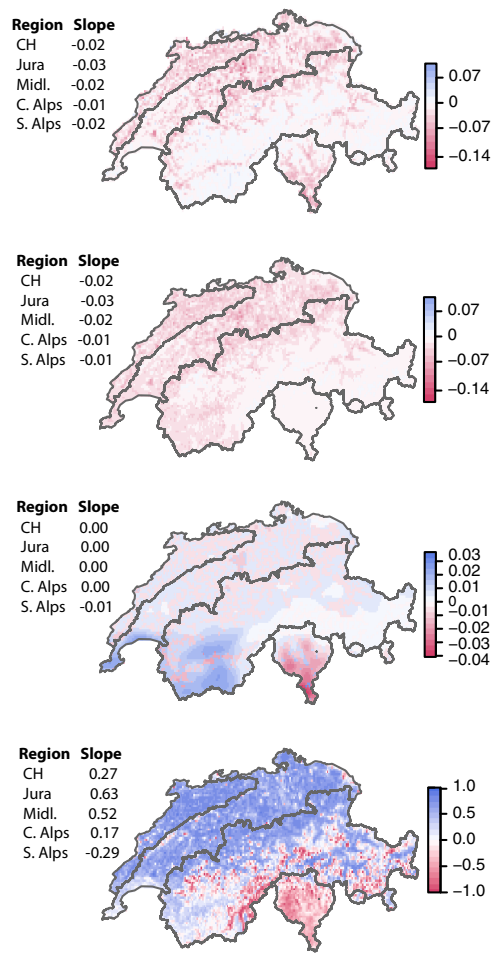

FIG. 3. (a) Observed ecosystem service (ES) trends between 2004 and 2014, explained by effects of (b) climatological drivers and (c) non-climatological drivers. (d) The standardized ratio of effects by climatological and non-climatological drivers represents the influence of (b) (positive, blue) and (c) (negative, red) on ES change. The tables contain average trends for Switzerland and its regions (CH, Switzerland; Jura; Midl., Midlands; C. Alps, Central Alps; S. Alps, Southern Alps). Note that, for visualization purposes, the scales of panel $\mathrm{c}$ differ from panels $\mathrm{a}$ and $\mathrm{b}$.

TABLE 2. Proportion of variance in ES trends explained by climatological drivers (deterministic component) $\left(R^{2}\right)$ in Switzerland and its regions and variable importance of the individual climatological drivers (i.e., temperature precipitation, rel. sunshine duration) to predict the modeled deterministic component in Switzerland.

\begin{tabular}{lccc}
\hline \hline Ecosystem service & $\begin{array}{c}\mathrm{CO}_{2} \\
\text { regulation }\end{array}$ & $\begin{array}{c}\text { Soil } \\
\text { erosion }\end{array}$ & $\begin{array}{c}\text { Air quality } \\
\text { regulation }\end{array}$ \\
\hline$R^{2}$ & & & \\
$\quad$ Jura & 0.67 & -0.62 & 0.71 \\
$\quad$ Swiss Midlands & 0.68 & -0.10 & 0.71 \\
Central Alps & 0.39 & 0.48 & 0.51 \\
$\quad$ Southern Alps & -0.52 & -0.17 & -0.11 \\
$\quad$ Switzerland & 0.40 & 0.63 & 0.54 \\
$\quad$ Variable importance & & & \\
$\quad$ Temperature & 0.34 & 0.35 & 0.52 \\
$\quad$ Precipitation & 0.31 & 0.31 & 0.32 \\
$\quad \begin{array}{l}\text { Relative sunshine } \\
\text { duration }\end{array}$ & 0.34 & 0.34 & 0.16 \\
\hline
\end{tabular}

explained by climatological drivers for all ES, while ES change in the Central Alps was less influenced by climatological drivers. All ES showed negative $R^{2}$ values in the Southern Alps and in the Swiss Midlands indicating that the deterministic model was not able to predict the effect of climatological drivers in these regions for these ES. The individual climatological drivers contributed diversely to the modeled deterministic components of the different ES in Switzerland (Table 2). All three climatological drivers were nearly equally important for $\mathrm{CO}_{2} \mathrm{R}$ and SEP. AQR was most affected by temperature that revealed the highest variable importance with 0.52 . Furthermore, precipitation was approximately twice as important as relative sunshine duration for $A Q R$.

The relationship between individual climatological drivers and the deterministic component revealed several negative, neutral, and positive directions (Fig. 4). For instance, all climatological drivers indicated positive effects on SEP. In contrast, AQR revealed mainly negative effects of climatological drivers except for a neutral interaction of AQR with temperature. Furthermore, $\mathrm{CO}_{2} \mathrm{R}$ was negatively influenced by precipitation, while temperature and relative sunshine duration revealed neutral effects.

\section{Effects of non-climatological drivers on ES change (spatial process $\mathrm{h}$ )}

The spatial process of the additive model described the spatial variation in ES trends that could not be 


\begin{tabular}{lccc}
\hline Climatology & $\begin{array}{c}\mathrm{CO}_{2} \\
\text { regulation }\end{array}$ & $\begin{array}{c}\text { Soil erosion } \\
\text { prevention }\end{array}$ & $\begin{array}{c}\text { Air quality } \\
\text { regulation }\end{array}$ \\
\hline Temperature & 0.07 & 0.30 & -0.09 \\
Precipitation & -0.14 & 0.49 & -0.28 \\
$\begin{array}{l}\text { Relative sunshine } \\
\text { duration }\end{array}$ & 0.04 & 0.42 & -0.22 \\
\hline
\end{tabular}

FIG. 4. Direction of the relationship between climatological drivers and the explained variation in ecosystem services based on the sign of the respective correlation coefficients. Red colors represent negative and blue colors positive correlations. The darker the color, the stronger is the correlation.

attributed to climatological drivers (Fig. 3c). These effects were smaller for all ES compared to the effect of climatological drivers. For all ES, the spatial variation of low negative and positive ES trends in the Jura and Swiss Midlands was attributed to the component representing non-climatological drivers. Also, stronger negative and positive ES trends in the Central and Southern Alps were captured by this non-climatological driver component. This also holds true for decreasing trends in the Southern Alps in $\mathrm{CO}_{2} \mathrm{R}$ and $\mathrm{AQR}$, and increasing trends in SEP in the southwestern Central Alps.

\section{Ratio of effects by climatological and non-climatological drivers}

The standardized ratio of effects by climatological and non-climatological drivers indicated the relative importance of both types of drivers to explain spatial variations of ES change. The results showed that ES trends were mainly attributed to changes in climatological drivers in Switzerland (positive values in Fig. 3d). In particular, trends in SEP were strongly affected by climatological drivers with an $R I$ value of 0.58 for Switzerland followed by $\mathrm{CO}_{2} \mathrm{R}(R I$ 0.42) and AQR (RI 0.27 ). Regional differences revealed that climatological drivers explained most of the ES trends in the Jura and Swiss Midlands for all ES and the changes in SEP in the Central and Southern Alps. Effects of non-climatological drivers dominated only local changes in $\mathrm{CO}_{2} \mathrm{R}$ and AQR in the Central and Southern Alps. However, these areas revealed also small-scale heterogeneity of climatological and non-climatological drivers. AQR showed a larger area with $R I$ values around zero in the southwest of the Central Alps.

\section{Discussion}

\section{Climatological drivers and ES change}

In general, there has been relatively little land use change in Switzerland over the investigated period (European Environmental Agency 2016, Swiss Federal Statistical Office 2016) and, consequently, trends in all ES were mainly attributed to climatological drivers in Switzerland. Explained effects of climatological drivers varied across ES and regions with mainly negative, but also positive influences on ES. The impact of climatological drivers over Switzerland explained well the negative $\mathrm{ES}$ trends in $\mathrm{CO}_{2} \mathrm{R}$ and $\mathrm{AQR}$, which is in line with other studies (Runting et al. 2017). Temperature was both positively and negatively correlated to $\mathrm{CO}_{2} \mathrm{R}$ in Switzerland with some spatially distributed positive effects on increasing $\mathrm{CO}_{2} \mathrm{R}$ trends in parts of the Central Alps. This positive effect of temperature on $\mathrm{CO}_{2} \mathrm{R}$ in the Swiss Alps can be explained by forest expansion into higher altitudes (Gellrich et al. 2007). The widely distributed negative $\mathrm{CO}_{2} \mathrm{R}$ trends across Switzerland could be equally attributed to changes in all three climatological drivers due to their similar variable importance. This indicates that temperature might have both positive and negative effects on $\mathrm{CO}_{2} \mathrm{R}$ trends, although spatially separated: positive in the Central Alps, where increasing temperature can have a strong effect on vegetation growth in higher altitudes, and negative in the other parts of Switzerland, where increasing temperature might be accompanied with a deficiency in water availability. Lu et al. (2013) detected such varying effects of temperature on carbon sequestration for different ecosystem types such as forest, grassland, shrubland, and tundra. This explanation also applies to our analysis, since small-scale heterogeneity in land use and land cover with different ecosystem types, exposition, and underlying environmental conditions characterizes Switzerland.

Trends in SEP were, on average, positively and equally affected by climatological drivers in Switzerland. This contradicts current findings of ES studies, where individual climatological drivers (i.e., temperature, precipitation, and relative sunshine duration) mainly revealed negative impacts on SEP and soil fertility (Runting et al. 2017). However, it seems that an increase in temperature (cf. Appendix S1: Fig. S1a) in Switzerland between 2004 and 2014 fostered vegetation growth and consequently an increase in SEP. Particularly in the Southern Alps and parts of the Central Alps, the positive effect of temperature even compensated an expected decrease in SEP caused by increasing precipitation (Appendix S1: Fig. S1b).

Furthermore, we attributed $54 \%$ of the trends in AQR to climatological drivers, with temperature contributing strongest to observed changes. Particularly in the Jura and Swiss Midlands, effects of climatological drivers dominated trends in $\mathrm{AQR}$, while effects of climatological and non-climatological drivers equally influenced $\mathrm{AQR}$ in the Central Alps. Observed dominance of climatological drivers in the Jura and the Swiss Midlands can be partly explained by negative effects of precipitation on AQR (Appendix S1: Fig. S1b). Negative effects of precipitation on $A Q R$ are also confirmed by another study investigating the impact of climate change attributes on particulate matter driven air quality (Jacob and Winner 2009). Temperature revealed a neutral effect and relative sunshine duration a negative effect on $\mathrm{AQR}$ changes, 
which contradicts Jacob and Winner (2009). It must be, however, noted that results in Jacob and Winner (2009) are based on few studies only and that particularly the effect of temperature is uncertain since temperature estimates are often too inaccurate.

The heterogeneous spatial pattern in ES trends was well captured in the modeled deterministic components, despite a few local over- and underestimates mainly located in the Southern Alps. The Southern Alps seemed to represent a special case with similar topography and ES provisioning as for the Central Alps, but with differences in climatological drivers. This caused problems in the deterministic model $g(x)$ resulting in local over- and underestimates. We acknowledge that our analysis regressed both long-term climate trends and interannual climate variability with ES supply. Our models convincingly showed that variability in climatological drivers affects the supply of ES from one year to the next, and that there is major spatial variability in this process. The investigated research period of $11 \mathrm{yr}$ was relatively short compared to what is needed to capture complex responses of ecosystems to climate change and related effects on ES. Hence, further research incorporating longer time series, is suggested to confirm how changes in ecosystems due to climate change affect the capacity of ecosystems in generating ES.

\section{Non-climatological drivers and ES change}

Effects of non-climatological drivers explain ES trends in Switzerland to a smaller magnitude compared to effects of climatological drivers. Particularly for $\mathrm{CO}_{2} \mathrm{R}$ and AQR, effects of non-climatological drivers dominantly explained ES trends but only in spatially restricted areas in the Central Alps ES. This might be attributed to small-scale land cover and land use change in Switzerland, which is in general almost negligible considering the whole area of the country in the investigated period (Swiss Federal Statistical Office 2016). Indeed, changes in CORINE land cover maps between 2006 and 2012 revealed very few differences, while no hotspot areas of land cover change can be identified in Switzerland (European Environmental Agency 2016).

Additionally, decreasing $\mathrm{PM}_{10}$ concentrations due to reduced $\mathrm{PM}_{10}$ emissions in Switzerland between 2004 and 2014, particularly in the southern part of Switzerland (Appendix S1: Fig. S3), and a decline in natural and remote landscapes could cause the observed influence of non-climatological drivers on AQR trends. However, the detected influence of non-climatological drivers could be partly associated with artifacts in the spatial process $(h)$ model compensating for possible overestimates of the deterministic component $(g(x))$. The deterministic component obtained higher trends in these areas compared to observed ES trends and represents an overestimate. Indeed, effects of non-climatological drivers seemed to cause observed increasing trends in AQR in the southwest of the Swiss Midlands and the Central
Alps. However, trends of the deterministic component exceeded observed AQR trends in these areas, representing an artifact due to an overestimation of the modeled deterministic component.

Slightly dominating effects of non-climatological drivers caused a decrease in $\mathrm{CO}_{2} \mathrm{R}$ in the Southern Alps. The effective non-climatological driver determining these negative trends is unclear; potential explanations are land use changes, an underestimation of the deterministic component resulting in artifacts in the explained variance of the non-climatological driver, and further processes that are unknown. Increasing $\mathrm{CO}_{2} \mathrm{R}$ trends explained by effects of non-climatological driver might be the result of an underestimated deterministic component. Additionally, interactions between effects of climatological and non-climatological drivers, for example, of climate and land use change, might be another reason for the observed $\mathrm{CO}_{2} \mathrm{R}$ trends.

Effects of non-climatological drivers also influenced SEP trends in the Central and Southern Alps and particularly explained spatial patches with relatively high SEP trends. Potential explanations for these SEP trends could be land cover changes, e.g., due to afforestation, and changes in ecosystem management that might have caused an increase in vegetation cover.

\section{Reliability of the analysis}

Applied remote sensing based time series of ES enabled detecting the impact of climatological and nonclimatological drivers on trends in ES supply. Since the investigated time series was relatively short with only $11 \mathrm{yr}$, we cannot rule out uncertainties in obtained trends of ES and climatological drivers due to anomalous years.

Modeled deterministic components estimating the contribution of climatological drivers on ES trends were based on random forest regression. The applied modelling accounted for non-linear effects in relationships between ES and climatological drivers. The interpretation of obtained results at regional scale indicated that the modeled deterministic component for the Southern Alps could not be estimated correctly using a random forest approach. Small-scale heterogeneity in trends of climatological drivers over all Switzerland caused prediction errors, because the deterministic model could not predict the resulting diversity of ES trends. Training and predicting the deterministic component per region and not at national scale could solve this problem (cf. Appendix S2). Consequently, explained effects of climatological and non-climatological drivers on ES trends should be carefully interpreted.

The deterministic model only considered climatological drivers but other drivers can be included too, for example land use change as one of the most frequently assessed non-climatological driver in ES studies (Nelson et al. 2010, Lawler et al. 2014, Egarter Vigl et al. 2016, Runting et al. 2017). The importance of land use change 
can be explained by its well-accepted relevance for ecosystem processes, the availability of land use change models, and found evidence on its negative impact on ES (Foley et al. 2005, Runting et al. 2017). Furthermore, many ES mapping approaches are built on land cover data (Lavorel et al. 2017), fostering research on future ES changes based on land cover scenarios (Nelson and Daily 2010, Nelson et al. 2010, Lawler et al. 2014, Martinez-Harms et al. 2017). The strong focus on land use change likely causes a bias by currently neglecting other possibly relevant drivers such as pollution and processes showing long-term dynamics (e.g., soil organic matter accumulation). Our analysis allowed disentangling effects of climatological from non-climatological drivers. We did not consider specific non-climatological drivers but our interpretation revealed a cumulative effect of non-climatological drivers beyond just the effect of land use change.

Analyzing climatological and non-climatological drivers and their effects on ES supply is critical for understanding the complexity involved in the driver impacts on ES (Carpenter et al. 2009, Bryan 2013). Our analysis contributes to this challenge by quantifying cumulative and individual contributions of climatological drivers to ES change, as well as the spatial structure of other nonclimatological drivers. Only a few studies (Runting et al. 2017, Schirpke et al. 2017) combined both types of drivers in their analysis, while most focused exclusively on climate change (Nelson et al. 2013, Scholes 2016) or land use change (Nelson et al. 2010, Schirpke et al. 2013, Stürck et al. 2015, Guerra et al. 2016b, MartinezHarms et al. 2017). Therefore, our analysis represents a step forward in tackling the challenge of investigating effects of both climatological and non-climatological drivers on ES. Furthermore, the investigation of cumulative and individual impacts of climatological drivers on ES has been limited so far (Runting et al. 2017), although it provides further insights and information that can improve management decision in landscape planning and conservation. Moreover, this information is also crucial for evaluating the progress towards policy targets such as the Aichi Biodiversity Targets and the Sustainability Goals and to provide guidelines for implementing the ES concept efficiently into practice (Cord et al. 2017).

\section{Conclusions And Outlook}

We demonstrated that an approach building on additive models offers new pathways to disentangle effects of climatological and non-climatological drivers on ES trends. We conclude that particularly the application of a random forest model as deterministic component allows compensating limitations of linear models by accounting for spatially heterogeneous ES trends as, for example, present in Switzerland. However, the random forest model is scale dependent and future work should consider adapting it for subscale analysis.
Our findings revealed that effects of climatological drivers on ES change in Switzerland are stronger compared to non-climatological drivers. In general, climatological and non-climatological drivers affected ES both negatively and positively, varying across the regions, drivers, and services assessed. In Switzerland, climatological drivers explained most of the trends in SEP followed by $\mathrm{AQR}$ and $\mathrm{CO}_{2} \mathrm{R}$. All three climatological drivers equally influenced trends in SEP and $\mathrm{CO}_{2} \mathrm{R}$, while temperature followed by precipitation mainly drove trends in AQR.

ES trends were mainly affected by climatological drivers in lower altitudinal areas (Jura and Swiss Midlands), and more strongly affected by non-climatological drivers in higher altitudes in the Central Alps. We consequently conclude on the importance of conducting regional ES monitoring and an associated analysis of the effects of relevant change drivers.

We suggest future research to extend the impact assessments of change drivers on biophysical ES supply to investigations of ES flow and demand. Additionally, we identify the need for advanced assessments considering the combined effects of climatological and non-climatological drivers on ES to systematically identify affected ES and their spatial locations and extent.

\section{ACKNOWLEDGMENTs}

D. Braun and A. Damm were supported by a grant of the Schweizer Staatssekretariat für Bildung, Forschung und Innovation in frame of the project Swiss Earth Observatory Network (KIP-5: SEON). The contributions of M. E. Schaepman, R. de Jong, and R. Furrer were supported by the University of Zurich Research Priority Program on "Global Change and Biodiversity."

\section{Literature Cited}

Braun, D., A. Damm, E. Paul-Limoges, A. Revill, N. Buchmann, O. L. Petchey, L. Hein, and M. E. Schaepman. 2017. From instantaneous to continuous: Using imaging spectroscopy and in situ data to map two productivity-related ecosystem services. Ecological Indicators 82:409-419.

Braun, D., A. Damm, L. Hein, O. L. Petchey, and M. E. Schaepman. 2018. Spatio-temporal trends and trade-offs in ecosystem services: An Earth observation based assessment for Switzerland between 2004 and 2014. Ecological Indicators 89:828-839.

Bryan, B. A. 2013. Incentives, land use, and ecosystem services: Synthesizing complex linkages. Environmental Science \& Policy 27:124-134.

Carpenter, S. R., et al. 2009. Science for managing ecosystem services: Beyond the Millennium Ecosystem Assessment. Proceedings of the National Academy of Sciences of USA 106:1305-1312.

Cord, A. F., K. A. Brauman, R. Chaplin-Kramer, A. Huth, G. Ziv, and R. Seppelt. 2017. Priorities to advance monitoring of ecosystem services using Earth observation. Trends in Ecology \& Evolution 32:416-428.

de Jong, R., M. E. Schaepman, R. Furrer, S. de Bruin, and P. H. Verburg. 2013. Spatial relationship between climatologies and changes in global vegetation activity. Global Change Biology 19:1953-1964. 
Díaz, S., et al. 2015. The IPBES conceptual framework-connecting nature and people. Current Opinion in Environmental Sustainability 14:1-16.

Didan, K. 2015. MOD13A1 MODIS/Terra Vegetation Indices 16Day L3 Global $500 \mathrm{~m}$ SIN Grid V006. NASA EOSDIS Land Processes DAAC. https://doi.org/10.5067/modis/mod13a1.006

Egarter Vigl, L., U. Schirpke, E. Tasser, and U. Tappeiner. 2016. Linking long-term landscape dynamics to the multiple interactions among ecosystem services in the European Alps. Landscape Ecology 31:1903-1918.

Egarter Vigl, L., E. Tasser, U. Schirpke, and U. Tappeiner. 2017. Using land use/land cover trajectories to uncover ecosystem service patterns across the Alps. Regional Environmental Change. https://doi.org/10.1007/s10113-017-1132-6

European Environmental Agency. 2016. CORINE Land Cover Change (LCC) 2006-2012, Version 18.5. https://land.copernic us.eu

Foley, J. A., et al. 2005. Global consequences of land use Science 309:570-574.

Gellrich, M., P. Baur, B. Koch, and N. E. Zimmermann. 2007. Agricultural land abandonment and natural forest re-growth in the Swiss mountains: A spatially explicit economic analysis. Agriculture, Ecosystems \& Environment 118:93-108.

Guerra, C. A., J. Maes, I. Geijzendorffer, and M. J. Metzger. 2016a. An assessment of soil erosion prevention by vegetation in Mediterranean Europe: Current trends of ecosystem service provision. Ecological Indicators 60:213-222.

Guerra, C. A., M. J. Metzger, J. Maes, and T. Pinto-Correia 2016b. Policy impacts on regulating ecosystem services: looking at the implications of 60 years of landscape change on soil erosion prevention in a Mediterranean silvo-pastoral system. Landscape Ecology 31:271-290.

Hein, L., C. Obst, B. Edens, and R. P. Remme. 2015. Progress and challenges in the development of ecosystem accounting as a tool to analyse ecosystem capital. Current Opinion in Environmental Sustainability 14:86-92.

Jacob, D. J., and D. A. Winner. 2009. Effect of climate change on air quality. Atmospheric Environment 43:51-63.

Jaeger, J. A. G., and C. Schwick. 2014. Improving the measurement of urban sprawl: Weighted Urban Proliferation (WUP) and its application to Switzerland. Ecological Indicators 38:294-308.

Karp, D. S., et al. 2015. National indicators for observing ecosystem service change. Global Environmental Change 35:12-21.

Kuhn, M. 2015. caret: Classification and regression training. https://CRAN.R-project.org/package $=$ caret

Lavorel, S., et al. 2017. Pathways to bridge the biophysical realism gap in ecosystem services mapping approaches. Ecological Indicators 74:241-260

Lawler, J. J., D. J. Lewis, E. Nelson, A. J. Plantinga, S. Polasky, J. C. Withey, D. P. Helmers, S. Martinuzzi, D. Penningtonh, and V. C. Radeloff. 2014. Projected land-use change impacts on ecosystem services in the United States. Proceedings of the National Academy of Sciences of USA 111:7492-7497.

Liaw, A., and M. Wiener. 2002. Classification and regression by randomForest. R News 2:18-22.

Lu, M., X. Zhou, Q. Yang, H. Li, Y. Luo, C. Fang, J. Chen, X. Yang, and B. Li. 2013. Responses of ecosystem carbon cycle to experimental warming: a meta-analysis. Ecology 94:726-738.

Manes, F., et al. 2016. Regulating ecosystem services of forests in ten Italian metropolitan cities: Air quality improvement by PM10 and O3 removal. Ecological Indicators 67:425-440.

Martinez-Harms, M. J., B. A. Bryan, E. Figueroa, P. Pliscoff, R. K. Runting, and K. A. Wilson. 2017. Scenarios for land use and ecosystem services under global change. Ecosystem Services 25:56-68.

Meacham, M., C. Queiroz, A. Norström, and G. D. Peterson. 2016. Social-ecological drivers of multiple ecosystem services: what variables explain patterns of ecosystem services across the Norrström drainage basin? Ecology and Society 21.

MeteoSwiss. 2016. Documentation of MeteoSwiss grid-data products - monthly and yearly precipitation: RhiresM and RhiresY. https://www.meteosuisse.admin.ch/content/dam/meteo swiss/de/service-und-publikationen/produkt/raeumliche-datenniederschlag/doc/ProdDoc_RhiresM.pdf

Millennium Ecosystem Assessment. 2005. Ecosystems and human well-being: the assessment series (four volumes and summary). Island Press, Washington, D.C., USA.

Mooney, H., A. Larigauderie, M. Cesario, T. Elmquist, O. Hoegh-Guldberg, S. Lavorel, G. M. Mace, M. Palmer, R. Scholes, and T. Yahara. 2009. Biodiversity, climate change, and ecosystem services. Current Opinion in Environmental Sustainability 1:46-54.

Mouchet, M. A., M. L. Paracchini, C. J. E. Schulp, J. Stürck, P. J. Verkerk, P. H. Verburg, and S. Lavorel. 2017. Bundles of ecosystem (dis)services and multifunctionality across European landscapes. Ecological Indicators 73:23-28.

Myneni, R., Y. Knyazikhin, and T. Park. 2015. MOD15A2H MODIS/Terra Leaf Area Index/FPAR 8-Day L4 Global $500 \mathrm{~m}$ SIN Grid V006. NASA EOSDIS Land Processes DAAC. https://doi.org/10.5067/modis/mod13a1.006

Nelson, E. J., and G. C. Daily. 2010. Modelling ecosystem services in terrestrial systems. F1000 Biology Reports 6:1-6.

Nelson, E., H. Sander, P. Hawthorne, M. Conte, D. Ennaanay, S. Wolny, S. Manson, and S. Polasky. 2010. Projecting global land-use change and its effect on ecosystem service provision and biodiversity with simple models. PLoS ONE 5. https:// doi.org/10.1371/journal.pone.0014327.

Nelson, E. J., et al. 2013. Climate change's impact on key ecosystem services and the human well-being they support in the US. Frontiers in Ecology and the Environment 11:483893.

Nowak, D. J. 1994. Air pollution removal by Chicago's urban forest. Pages 63-81 in E. G. McPhearson, D. J. Nowak, and R. A. Rowntree, editors. Chicago's urban forest ecosystem: results of the Chicago Urban Forest Climate Project. USDA Forest Service General Technical Report NE-186. USDA Forest Service, Radnor, Pennsylvania, USA.

Panagos, P., K. Meusburger, C. Ballabio, P. Borrelli, and C. Alewell. 2014. Soil erodibility in Europe: a high-resolution dataset based on LUCAS. Science of the Total Environment 479480:189-200

Panagos, P., et al. 2015. Rainfall erosivity in Europe. Science of the Total Environment 511:801-814.

Pebesma, E. J., and C. G. Wesseling. 1998. Gstat: a program for geostatistical modelling, prediction and simulation. Computers \& Geosciences 24:17-31.

Pilesjö, P., and A. Hasan. 2014. A triangular form-based multiple flow algorithm to estimate overland flow distribution and accumulation on a digital elevation model. Transactions in GIS 18:108-124

Polasky, S., E. Nelson, D. Pennington, and K. A. Johnson. 2011. The impact of land-use change on ecosystem services, biodiversity and returns to landowners: A case study in the state of Minnesota. Environmental and Resource Economics 48:219-242.

Raich, J. W., C. S. Potter, and D. Bhagawati. 2002. Interannual variability in global soil respiration, 1980-94. Global Change Biology 8:800-812.

Remme, R. P., M. Schröter, and L. Hein. 2014. Developing spatial biophysical accounting for multiple ecosystem services. Ecosystem Services 10:6-18.

Rosenzweig, C., et al. 2014. Assessing agricultural risks of climate change in the 21 st century in a global gridded crop model intercomparison. Proceedings of the National Academy of Sciences of USA 111:3268-3273. 
Rounsevell, M. D. A., T. P. Dawson, and P. A. Harrison. 2010. A conceptual framework to assess the effects of environmental change on ecosystem services. Biodiversity and Conservation 19:2823-2842.

Running, S., and M. Zhao. 2015. MOD17A2H MODIS/Terra Gross Primary Productivity 8-Day L4 Global $500 \mathrm{~m}$ SIN Grid V006. NASA EOSDIS Land Processes DAAC. https://d oi.org/10.5067/modis/mod17a2h.006

Runting, R. K., B. A. Bryan, L. E. Dee, F. J. F. Maseyk, L. Mandle, P. Hamel, K. A. Wilson, K. Yetka, H. P. Possingham, and J. R. Rhodes. 2017. Incorporating climate change into ecosystem service assessments and decisions: a review. Global Change Biology 23:28-41.

Schirpke, U., G. Leitinger, E. Tasser, M. Schermer, M. Steinbacher, and U. Tappeiner. 2013. Multiple ecosystem services of a changing Alpine landscape: past, present and future. International Journal of Biodiversity Science, Ecosystem Services \& Management 9:123-135.

Schirpke, U., M. Kohler, G. Leitinger, V. Fontana, E. Tasser, and U. Tappeiner. 2017. Future impacts of changing land-use and climate on ecosystem services of mountain grassland and their resilience. Ecosystem Services 26:79-94.

Scholes, R. J. 2016. Climate change and ecosystem services. Wiley Interdisciplinary Reviews: Climate Change 7:537550 .
Schröter, M., D. N. Barton, R. P. Remme, and L. Hein. 2014. Accounting for capacity and flow of ecosystem services: A conceptual model and a case study for Telemark, Norway. Ecological Indicators 36:539-551.

Stürck, J., C. J. E. Schulp, and P. H. Verburg. 2015. Spatiotemporal dynamics of regulating ecosystem services in Europe - the role of past and future land use change. Applied Geography 63:121-135.

Swiss Federal Office for the Environment. 2015. Karten von Jahreswerten der Luftbelastung in der Schweiz. Swiss Federal Office for the Environment, Bern, Switzerland.

Swiss Federal Statistical Office. 2016. Taschenstatistik der Schweiz 2016. Swiss Federal Statistical Office, Neuchâtel, Switzerland.

TEEB. 2010. The Economics of Ecosystems and Biodiversity: Mainstreaming the Economics of nature: a Synthesis of the Approach, Conclusions and Recommendations of TEEB. Available: http://www. teebweb.org/our-publications/teebstudy-reports/synthesis-report/

United Nations. 2014. System of Environmental-Economic Accounting 2012 : Experimental Ecosystem Accounting. New York, USA.

Zinke, P. J. 1967. Forest interception studies in the United States. Pages 137-161 in W. E. Sopper and H. W. Lull, editors. Forest Hydrology. Pergamon Press, Oxford, UK.

\section{SUPPORTING INFORMATION}

Additional supporting information may be found online at: http://onlinelibrary.wiley.com/doi/10.1002/eap.1901/full

\section{Data Availability}

Data are available on the Zurich Open Repository and Archive (ZORA): https://doi.org/10.5167/uzh-170517. 